Combined Spinal and Splanchnic Anaesthesia.

For abdominal operations in the neighbourhood of the diaphragm-for example, partial gastrectomy, gastro-enterostomy, resection of growths of the transverse colon and the flexures, operations on the gall-bladder and ducts-spinal anaesthesia with 0.1 gram stovaine introduced between tho second and third lumbar vertebrae combined with splanchnis anaesthesia (60 to $70 \mathrm{c.cm}$. of a $0.5 \mathrm{per}$ cent. solution of novocain), given according to Braun's method, is the anaesthetic of choice. The combination is used because, for operations lasting over an hour, spinal anaesthesia by itself is not sufficient. The anaesthesia can be prolonged if necessary by administering a further dose of the splanchnic anaesthetic and infiltrating tho peritoneum and abdominal muscles with 0.5 per cent. novocain in 1 in 200,000 adrenaline solution. To nervous patients about to undergo an operation which is likely to be prolonged we have given, in addition to the spinal anaesthetic, a dose of avertin by the rectum sufficient to produce a quiet slcep, and thus uinconsciousness of the surroundings and of the heat, whici some patients find distressing. This anaesthetic combination has the following advantages:

1. It secures complete and uniform muscular relaxation.

2. Diaphragmatic movements are damped down to a minimum.

3. There is a marked absence of post-operative shock.

4. The anaesthetic is non-toxic.

5. Post-anaesthetic vomiting and chest complications do not occur.

Professor Finsterer, whom I have watched and assisted at his work in Vienna, would take three hour's or more to perform the extensive operation of partial resection of the stomach for jejunal ulcer following previous gastro-enterostomy, using block anaesthesia to enter tho peritoneal cavity, and splanchnic anaesthesia as advocated by Braun; he would repeat the splanchnic anaesthetic, but never more than once. I visited the subjects of these operations afterwards and found very little evidence of post-operative shock. Moreover, inhalation narcosis could not have secured the certain and continued relaxation and the safety rendered possible by the above measures.

\section{Spinal Anacsthesia.}

For operations about and below the umbilicus-for example, in acute appendicitis, acute intestinal obstruction, strangulated umbilical hernia, pelvic operations in the female, operations on the bladder, excision of the rectum, haemorrhoids, and so forth-spinal anaesthesia, achieved by introducing 0.05 to 0.1 gram of stovaine into the theca between the third and fourth lumbar vertebrae, is the method of choice. It is also ideal for all operations of magnitude on the lower extremities, and has the same advantages as the anaesthetic combination described above. In operations for intestinal obstruction spinal anaesthesia confers an added advantage: the caecum can be exposed without escape of viscera, and if distended it can be tapped. The action of stovaine being to cause strong and active peristalsis, the tapping is followed by rapid cmptying of the gut. In cases of intestinal obstruction it is more than ever essential to use an anaesthetic of minimum toxirity but affording complete and uniform muscular relaxation.

Infiltration and Block Anaesthesia.

This anaesthetic (solution of novocain 0.5 per cent. in adrenaline 1 in 200,000) has been freely used alone in such instances as strangulated herniae in very old bronchitic subjects, for caecostomy in cases of acute intestinal obstruction where the toxic effects are very marked, and for amputation for gangrene in old people who have accompanying serious constitutional complications. For removal of superficial tumours-for example, lipomata, etc.-infiltration anaesthesia is the one of choice.

Avertin.

I first saw this compound used in Berlin by Professor Katzenstein in December, 1927, and was impressed by its properties; I have since used it in over a hundred cases, and find that, though not in itself a complete analgesic, it is a powerful amnesic. It is useful in combination. with infiltration anaesthesia in adults and older. children, and with light ether anaesthesia in younger children. Combined with infiltration anaesthesia it may be used in rases of operation for goitre, appendicitis, hernia, excision of the breast, and so forth. It is entirely non-toxic, and must find a useful place both in general surgery and obstetric practice.

For the reduction of fractures avertin in combination with local anaesthesia is ideal, and is used extensively on the Continent; 50 to $60 \mathrm{c.cm}$. of 0.05 per cent. novocain solution in 1 in 200,000 adrenaline are injected into the blood clots surrounding the fractured ends of the bone. The surgeon, having ensured that his needle has entered the blood clot by withdrawing blood-stained fluid into the syringe, may carry out the necessary manipulations in a perfectly painless manner five to ten minutes after the injection.

I would say in conclusion that since using the abovedescribed method of anaesthesia $I$ have witnessed a 50 per cent. fall in the mortality from my abdominal operations. I hope the time is not far distant when ether and chloroform narcosis with their inevitable mortality will have been superseded.

$$
\begin{aligned}
& \text { REFERENCK. } \\
& { }^{1} \text { British Medical Journal, March 2nd, 1929, p. } 398 .
\end{aligned}
$$

\section{APPARENTLY SPONTANEOUS RUPTURE OF THE NORMAL SPLEEN.}

\section{BY}

D. H. PATEY, M.S., F.R.C.S., SURGEON TO OUT-PATIENTS, HAMPSTEAD GENERAL HOSPITAL.

$I_{T}$ is a fact well known to all surgeons that in various pathological conditions, of which chronic malaria affords the best example, the spleen may rupture following the slightest degree of trauma, or even without injury at all. To the latter condition tho ter'm "spontaneous rupture" is applied. Rare cases have been reported in which it is claimed that a similar spontaneous rupture has taken place in a perfectly normal spleen. That a healthy spleen should without apparent cause suddenly burst is difficult of belief, and the following case is recorded as offering an explanation of the anomaly.

The patient was a fairly well-covered and muscular male, aged 50, by occupation a shopkeeper. He stated that he had previously been quite healthy, and that he was one of a large family all of whom were healthy. He gave a history that on the evening of March 12th, 1927, he suddenly, and without apparent cause, experienced acute pain in the epigastrium, which within a few minutes became so severe that he had to stop work. The pain later spread to both his shoulders. He went to bed, but was not seen by his doctor until March 14th, when he was immediately ordered to hospital.

On admission the patient looked extremely ill, his face being pale and covered by a cold sweat. The temperature was $93^{\circ} \mathrm{F}$., and the pulse 120 ; the respirations were shallow and grunting. The tongue was slightly furred. The abdomen did not move on respiration, and was uniformly rigid to superficial palpation. Deep tenderness was present all over the abdomen, being most marked in the epigastrium. A rectal examination was negative. The patient was regarded as a typical case of perforated gastric ulcer, which diagnosis was made independently by his doctor, the housc-surgeon, and the surgeon.

Opcration (March 14th).-The abdomen was opened by a right paramedian upper abdominal incision. Immediately on opening the peritoneum there was a profuse outpouring of blood, at first dark and old, but later mixed with fresh blood. Investigation showed the spleen to he the source of the haemorrhage, and this organ was removed after the left rectus muscle had been divided transversely to obtain better access. The patient was by this time very collapsed; an intravenous saline was therefore given on the table, while the abdomen was rapidly closed with throughand-through sutures. The patient rallied well from the operation, and had a normal uneventful convalescence. He was discharged on April 11th.

Macroscopical Appcarance of the Spleen.-The normal apvearances of the spleen were almost completely obscured by two large subcapsular haematomata, one situated on the outer convex surface, the other on the concave side of the organ, the two communicating with each other round the posterior border. The only normal spleen visible was a narrow strip along the anterior border. The haematoma on the convex aspect of the organ had ruptured through the capsule at one point, and it was through this rupture that the haemorrhage into the abdomen had taken 
place. The vesscls in the hilum of the organ appeared healthy. On section the diagnosis of subcapsular haematoma was confirmed, and it was in addition seen that a considerable portion of the splenic substance had been ploughed up by the haemorrhage.

Microscopical Examination.-A portion of the spleen which appeared to be undamaged by the haemorrhage was submitted to microscopical examination. A normal histological picture was found. A portion of the splenic artery was also examined, but no abnormality was discovered.

As far as could be judged, therefore, apart from the damage caused by the haemorrhage, the spleen was a normal healthy organ of the usual size and with healthy blood ressels. The patient was repeatedly questioned as to whether he had received any injury, but this was denied. A diagnosis was therefore made of spontaneous rupture of a normal spleen.

Shortly after his discharge the patient was asked to attend in order that he might be further examined, and investigations were made to see if some cause could be discovered to account for the apparently spontaneous rupture. No abnormal signs were found in the heart, lungs, or abdomen. The urine was acid, and contained no abnormal constituents. The arteries were slightly thickened and the blood pressure was $140 / 85$. While the examination was in progress the patient stated that he had lately rcmembered that at $10.30 \mathrm{a} . \mathrm{m}$. on the day of the onset of his illness he was leaning over a ledge in order to open his shop window, when he slipped and fell on to his left side against the edge of the ledge. He had only slight discomfort, and, thinking nothing of his injury, dismissed it from his mind until our repeated questionings recalled the incident. Undoubtedly this forgotten trauma was the primary cause of the ruptured spleen.

Similar cases have been reported by T. S. Jackson ${ }^{2}$ and J. L. Stretton. ${ }^{2}$ Jackson's patient was a girl, aged 15, in whom the apparent spontaneous rupture occurred while she was sitting in a cinema. After her recovery he elicited the history that four weeks previously she had fallen against a desk, striking her left side. Stretton's patient was a pregnant woman, aged 37, in whom the lesion professedly followed the getting out of bed to pass urine. Subsequent careful inquiry elicited a story of violent coitus.

M. P. Susman ${ }^{3}$ reports, as a spontaneous rupture of an apparently normal spleen, a case the clinical features of which bear a close resemblance to the one recorded here, and in which the original diagnosis was also porforated gastric ulcer. He could find only six similar cases in the literature.

Admitting that spontaneous rupture of a perfectly healthy spleen can hardly occur, he suggests as an explanation that some lesion was present which was responsible for the rupture, though evidence of its existence was destroved by that occurrence. In other words, we are dealing with examples of spontaneous rupture of pathological spleens. It seems simpler to believe that occasionally, in certain individuals and at certain phases, rupture of a normal spleen may occur following minimal trauma. If the capsule is intact the symptoms may be delared for hours or days, and when eventually the patient collapses the memory of the original and causative injury has disappeared. The case here recorded affords a good example of this happening.

REFERENCES.

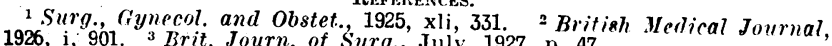

\section{A NOTE ON HAEMATOCOLPOS. With a Report of Two Cases.}

BY

Albert Sharman, B.Sc., M.B., Ch.B.Glasg.,

LATE RESIDENT SURGEON, ROYAL ALEXANDRA INFIRMARY, PAISLEY; EXTRA DISPENSARY SURGEON, ROYAL SAMARITAN HOSPITAL FOR WOMEN, GLASGOW.

Hammatocolpos is a very uncommon affection, and is the result, generally, of cryptomenorrhoea, the condition in which the formation of the menstrual discharge goes on, but without the normal appearance of menstruation. Two cases which recently came under my notice and presented features of much interest prompt a review of the general points and symptomatology of the condition.

The patient is generally between 15 and 18 years of age, ${ }^{1}$ and is usually brought to medical notice on account of one or ather of three things: (1) non-appearance of menstrual periods; (2) swelling in the abdomen; (3). disturbance of
In most cases subjective srmptoms of the menstrual period are present, and these tend to be better defined in older girls. The obstruction to the escape of the menstrual discharge may be anywhere below the internal os, and its commonest site is the ostium vaginae, where a diaphragm is present, formed by the non-canalization of the lower end of the fused Müllerian ducts, and not by an imperforate hymen. ${ }^{3}$ In some cases the normal hymen mav be seen external to the obstructing membrane, but in others there is no trace of the hrmen whatsoever, and some olservers have described this type as due to a true imperforate hymen.

De Sahn ${ }^{4}$ many years ago, in a review of the condition, stated that the error of formation is nerer very great, as it would then promote atrophy of the internal genitals, especially of the ovaries, and menstruation would not occur. He pointed out factors leading to stenosis of the raginal canal, such as inflammatory or specific ulceration of the ragina, chronic vaginitis, cicatricial constriction following injuries during labour, or an attack of small-pox or typhoid ferer, and, possibly, cancer obstructing the vagina. These latter cases must be rery rare and may be considered separately from those under consideration now, which can be conveniently termed primary or membranous haematocolpos.

The patient, a girl aged 13 years and $8 \frac{1}{2}$ months, was admitled to Paisley Royal Alexandra Infirmary on January 17th, 19?9, under the care of Mr. Hugh Donald.

History.-Four months before admission to hospital the girl complained of slight pain in the abdomen. This persisted for an afternoon, during which her mother detained her from school. Between thrce and four weeks later slight pain recurred, and lasted for about three hours; it was not severe enough to keep her from attending school. Another mild attack appeared between three and four weeks later, and, like the others, was referrd to the " middle of the stomach and low down." A similar interval elapsed until the next attack, which was more severe than the other's, but only lasted about four hours. The next spasm occurred three weeks later, and was sufficiently severe to make her seek medical advice, and to be detained in hospital. Five days before admission she had a sharp and moderately severe epistaxis, with no accompanying symptoms. The following morning she was given Epsom salts at home, and in the evening complained of slight pain in the abdomen, similar to that which she had previously been experiencing, but which her mother attributed to the purgation. The next afternoon she was crying with the pain, which persisted all the evening. On the following day the pain was still more severe; it was situated just below the umbilicus, and for the first time necessitated her remaining in bed. Her mother stated that the pain seemed to be cramp-like, as, at short intervals, the girl would cry out as a painful spasm occurred. This persisted until the next day, when pain on micturition became an added feature. The painful micturition and spasmodic atlacks of evidently severe pain, causing her to roll about in agony in bed, made her fami!y doctor suspect urinary calculus, and he sent her to hospital.

On examination the patient was found to be a well-nourished and well-cleveloped girl, the secondary sex characters being well formed. Decp tenderness was elicited in the middle line of the abdomen between the symphysis pubis and one inch below the umbilicus, and this tenderness was also present, extending for about two inches from the mid-line on the left side, but not on the right. A distinct mass could be felt in this situation through the abdominal wall, but its outline could not be defined. Rectal examination proved excessively tender, but a large, soft swelling was readily made out, bulging into the anterior rectal wall, and haematocolpos was diagnosed. When the condition is kept in mind, diagnosis is simple. While in the ward before operation she had one severe spasm of pain, which was relieved by 5 grains of aspirin. There was no albuminuria.

Trcatment.-Under anaesthesia, examination of the hymen revealed it to be bulging, deep red in colour, and quite imperforate. A very freety movable tumour was palpated through the abdominal wall with its upper border about one inch from the umbilicus. The abdomen was opened in the mid-line and the tumour found to be the uterus distended with blood; the ovaries and tubes were examined and found normal. Laparotomy was justified to observe the condition of the Fallopian tubes, as haematosalpinx would most probably have necessitated their removal. The hymen was vertically incised under scrupulous asepsis, and one pint of dark red, jelly-like fluid escaped. The external os of the cervix admitted one finger readily. The condition was, then, haematometra. The vulva was swabbed with spirit and iodine, but no raginal cleansing was emploved. The vulva was swabbed with spirit daily, and the patient made an uninterrupted recovery, being dismissed on February 86th. Menstruation, to that date, had not yet reappeared. 